OPEN ACCESS

Edited by:

Sarah M. Temkin,

National Cancer Institute, USA

Reviewed by:

Reuven Reich,

Hebrew University of Jerusalem,

Israel

Brigitte Mlineritsch, Private Medical University Clinic

Salzburg, Austria

${ }^{*}$ Correspondence: Jessica L. Krok-Schoen jessica.krok@osumc.edu

Specialty section: This article was submitted to Women's Cancer. a section of the journal

Frontiers in Oncology

Received: 09 November 2015 Accepted: 03 January 2016 Published: 28 January 2016

Citation:

Krok-Schoen JL, Oliveri JM and Paskett ED (2016) Cancer Care Delivery and Women's Health: The Role of Patient Navigation. Front. Oncol. 6:2. doi: 10.3389/fonc.2016.00002

\section{Cancer Care Delivery and Women's Health: The Role of Patient Navigation}

\author{
Jessica L. Krok-Schoen ${ }^{1 *}$, Jill M. Oliveri ${ }^{1}$ and Electra D. Paskett ${ }^{1,2,3}$ \\ ${ }^{1}$ Comprehensive Cancer Center, The Ohio State University, Columbus, OH, USA, ${ }^{2}$ Division of Cancer Prevention and \\ Control, Department of Internal Medicine, College of Medicine, The Ohio State University, Columbus, OH, USA, \\ ${ }^{3}$ Division of Epidemiology, College of Public Health, The Ohio State University, Columbus, OH, USA
}

Background: Patient navigation (PN) is a patient-centered health-care service delivery model that assists individuals, particularly the medically underserved, in overcoming barriers (e.g., personal, logistical, and system) to care across the cancer care continuum. In 2012, the American College of Surgeons Commission on Cancer (CoC) announced that health-care facilities seeking $\mathrm{CoC}$-accreditation must have $\mathrm{PN}$ processes in place starting January 1, 2015. The CoC mandate, in light of the recent findings from centers within the Patient Navigation Research Program and the influx of PN interventions, warrants the present literature review.

Methods: PubMed and Medline were searched for studies published from January 2010 to October 2015, particularly those recent articles within the past 2 years, addressing PN for breast and gynecological cancers, and written in English. Search terms included patient navigation, navigation, navigator, cancer screening, clinical trials, cancer patient, cancer survivor, breast cancer, gynecological cancer, ovarian cancer, uterine cancer, vaginal cancer, and vulvar cancer.

Results: Consistent with prior reviews, PN was shown to be effective in helping women who receive cancer screenings, receive more timely diagnostic resolution after a breast and cervical cancer screening abnormality, initiate treatment sooner, receive proper treatment, and improve quality of life after cancer diagnosis. However, several limitations were observed. The majority of PN interventions focused on cancer screening and diagnostic resolution for breast cancer. As observed in prior reviews, methodological rigor (e.g., randomized controlled trial design) was lacking.

Conclusion: Future research opportunities include testing PN interventions in the post-treatment settings and among gynecological cancer patient populations, agerelated barriers to effective $\mathrm{PN}$, and collaborative efforts between community health workers and patient navigators as care goes across segments of the cancer control continuum. As PN programs continue to develop and become a standard of care, further research will be required to determine the effectiveness of cancer PN across the cancer care continuum, and in different patient populations.

Keywords: patient navigation, breast cancer, cervical cancer, gynecological cancers, women's health, cancer disparities 


\section{INTRODUCTION}

Profound advances in cancer screening, reductions in the prevalence of risk factors, and development of more effective treatments have positively contributed to increased longevity and quality of life among cancer survivors. Despite these improvements, disparities by race/ethnicity and socioeconomic status remain in cancer prevention, incidence, treatment, and mortality $(1,2)$. One approach to reduce cancer disparities is through patient navigation (PN). PN is a patient-centered, health-care service delivery model that assists individuals, particularly the medically underserved, in overcoming barriers to care (e.g., personal, logistical, system) across the cancer care continuum. $\mathrm{PN}$ is "navigation" in the health-care system compared to outreach, which is in the community and can use lay health advisors, community health workers (CHWs), etc. Typically, CHWs are trusted community members who provide information, support, and encouragement to receive screening tests (3). Previous intervention studies using CHWs to promote cancer screening have reported significantly increased screening rates for breast and cervical cancer $(3,4)$. CHWs and patient navigators differ in that CHWs work in the community, and their role ends when the patient enters the health-care facility. Patient navigators are typically housed in clinics; however, both the CHW and patient navigator complement each other in that they serve as a bridge between the health-care system and members of underserved communities.

Patient navigation began in 1990 by Harold Freeman who developed a PN program within a public hospital in Harlem, NY, USA to provide assistance to low-income women in need of breast cancer screening and timely follow-up to reduce diagnoses of late-stage breast cancer (5). Due to the promising results from Freeman's initial PN program and continued evidence of effectiveness, PN has grown nationally as a standard of care (6, 7). PN studies have demonstrated that PN can improve rates of cancer screening $(8,9)$, ensure follow-up rates after an abnormal screening test $(10,11)$, and improve cancer care outcomes (i.e., time to treatment, quality of life) $(12,13)$.

Several recent literature reviews including Robinson-White et al. (14), Paskett et al. (15), and Wells et al. (16) have described the evolution of PN as a model to address cancer disparities. In 2011, a literature review by Paskett et al. (15) provided an update to the 2008 review by Wells et al. (16) on the efficacy of PN for cancer care. Paskett et al. (15) found that within the 3-year window since Wells' review, the quantity of work in cancer PN literature was comparable to that of the previous years combined. In both reviews, most studies provided evidence for the effectiveness of increasing cancer screening rates including breast and gynecological cancers $(15,16)$. However, a paucity of research focusing on PN among cancer survivors during and after primary treatment and methodological limitations (i.e., lack of rigorous study design) of PN interventions were noted.

Since the 2011 literature review, many additional PN programs have been implemented especially those within the Patient Navigation Research Program (PNRP), funded by the National Cancer Institute (17) with support from the American Cancer Society (ACS). Active from 2005 to 2010, the PNRP provided funding to 10 institutions nationwide to develop and test interventions for follow-up and the initiation of treatment for four cancers for approved, validated screening tests: breast, cervical, prostate, and colorectal (18). Although any individual could benefit from PN, the PNRP focused efforts to identify and address barriers to care among populations experiencing cancer health disparities.

Breast and gynecological cancers are an optimal arena to use PN because of the known survival benefit of early detection through mammography and Pap tests with prompt follow-up of detected abnormalities. PN is particularly important in women's cancers because of documented racial and ethnic disparities in cancer care across disease trajectories. In 2015, cervical cancer incidence rates among Hispanic women were the highest of any racial/ethnic group, 50\% higher than those among non-Hispanic whites (19). In addition, the death rate for cervical cancer in black women was double than that in non-Hispanic white women (2.0 vs. 4.2 per 100,000 , respectively) (19). It is notable that although white women had the highest breast cancer incidence rate, black women had the highest breast cancer mortality rate $(19,20)$. Thus, PN may be a strategy to help reduce these documented disparities.

The purpose of this review is to: (a) provide a summary of the recent literature (2010-2015) on PN and breast and gynecologic cancers from screening through treatment along the cancer care continuum; and (b) highlight research challenges and opportunities of PN that impact women's health.

\section{METHODS}

PubMed and Medline were searched for studies published from January 2010 to October 2015, particularly those recent articles within the past 2 years, addressing PN for breast and gynecological cancers and written in English. Only original studies reporting quantitative, qualitative, or mixed methods results regarding PN that dealt with cancer screening, diagnosis, treatment, clinical trials, or survivorship were included in this review. Editorials, abstracts, anecdotal reports, literature reviews, and articles lacking data from original research were excluded, as were articles that included non-breast/non-gynecological cancers and/or men in the analyses. Search terms included patient navigation, navigation, navigator, cancer screening, clinical trials, cancer patient, cancer survivor, breast cancer, gynecological cancer, ovarian cancer, uterine cancer, vaginal cancer, and vulvar cancer.

A total of 209 articles referencing PN in women's cancers were found, of which 180 did not meet the inclusion criteria, resulting in 29 articles that met the criteria for inclusion in this review. Several notable PNRP articles were excluded because they included non-breast/non-gynecological cancer and men in their analyses (21-25). The 29 articles were then divided into categories along the cancer care continuum (screening, diagnostic resolution, and after primary diagnosis). The articles were reviewed and summarized by one study author (Jessica L. Krok-Schoen). Questions regarding inclusion were resolved by consensus among the other two authors (Jill M. Oliveri and Electra D. Paskett). Each article was reviewed, and the results presented are organized by placement along the cancer care continuum described above. 
Table 1 comprises a summary of published cancer PN studies $(N=29)$.

\section{RESULTS}

\section{PN for Cancer Screening}

The literature on $\mathrm{PN}$ interventions to increase breast cancer screening included five studies (26-30), with two randomized controlled trials (RCTs) $(27,30)$. In a large RCT with 3,895 inner city women, Phillips et al. (30) found no statistical difference in mammography adherence between the control (usual care) and PN intervention groups at baseline. After the 9-month intervention, mammogram adherence was significantly higher in the PN intervention group compared to the control group (87 vs. $76 \%$, respectively, $p<0.001$ ). Marshall et al. (27) implemented a RCT to increase breast cancer screening among 1,905 older African American Medicare beneficiaries. Women in the intervention group who received educational materials and PN services had significantly higher odds of being within guidelines for mammography screening at the end of the 2-year follow-up period compared to women in the control group who received only educational material [odds ratio $(\mathrm{OR})=2.26$, 95\% confidence interval $(\mathrm{CI})=1.59-3.22]$.

The other three studies $(26,28,29)$ examined the effectiveness of PN interventions to increase breast cancer screening among diverse populations, including African American, Latina, Native American (26), immigrant $(28,29)$, and refugee $(28,29)$ women. Burhansstipanov et al. (26) implemented an education-based PN intervention to facilitate mammography screening for African American, Latina, Native American, and poor white women in the Greater Denver Metropolitan area. Statistically significant associations were found between having received the $\mathrm{PN}$ intervention and reporting a mammogram screening for all racial/ethnic groups $(p<0.05)$. A study by Percac-Lima et al. (28) implemented an educational, language concordant PN program for Serbo-Croatian refugees and immigrants to overcome barriers to breast cancer screening and support them in scheduling a mammogram. They found that, at baseline, $44 \%$ of women had a mammogram within

TABLE 1 | Summary of published cancer patient navigation studies: 2010-2015.

\begin{tabular}{llll}
\hline Reference Cancer Design & Participants & Results
\end{tabular}

\section{PATIENT NAVIGATION FOR CANCER SCREENINGS}

Burhansstipanov Breast et al. (26)

Marshall et al. (27) Breast

Natural experiment then a quasi-control study

Randomized controlled trial

Percac-Lima et al. Breast (28) (29)

Percac-Lima et al. Breast Quasi-

Phillips et al. (30) Breast Controlled

cluster randomized tria

Wang et al. (31) Cervical Two-arm, quasiexperimental pilot study
313 African American, Latina, Native American, and poor White women who had not received a mammography in more than 18 months enrolled in a navigation intervention

1,358 African American female Medicare beneficiaries who were $\geq 65$ years of age randomized to receive either patient navigation and educational materials $(n=638)$ or educational materials only $(n=720)$ 91 Serbo-Croatian speaking women overdue or never had a mammogram who received individually tailored interventions to encourage breast cancer screenings

188 refugee women eligible for breast cancer screening at an urban community health center. The comparison group was English $(n=2,072)$ or Spanish-speaking ( $n=2,014)$ women eligible for breast cancer screening

3,895 inner city women were randomized to a phone-based navigation intervention ( $n=1,817)$ and usual care $(n=2,078)$ groups

Chinese women ( $n=134)$ who has not had a Pap test within the previous 12 months assigned to either patient navigation (education and navigation services) ( $n=80)$ and control (education only) $(n=54)$ groups

\section{PATIENT NAVIGATION FOR DIAGNOSTIC RESOLUTION}

$\begin{array}{ll}\text { Basu et al. (32) Breast } & \text { Pre-post } \\ & \text { design, quasi- } \\ & \text { experimental }\end{array}$
intervention
176 women diagnosed with breast cancer enrolled in a nurse navigation program to increase timeliness to diagnostic resolution and consultation
Navigation improved mammography among women for all racial/ ethnic groups who received the navigation intervention compared to those women in the non-navigated group

Women in the intervention group had significantly higher odds of being up to date on mammography screening compared to women in the education only group $(\mathrm{OR}=2.26$, $95 \%$ $\mathrm{Cl}=1.59-3.22)$

At baseline, $44.0 \%$ of women had a mammogram within the previous year, with the proportion significantly increasing to $67.0 \%$ after 1 year $(p<0.001)$

Patient navigation increased screening rates in both younger and older refugee women (64.1\% before intervention, $81.2 \%$ after intervention) and were similar to the English (80.0\%) and Spanishspeaking women $(87.6 \%)$

At baseline, there was no difference in mammography adherence between the usual care and intervention groups. After the 9-month intervention, mammogram adherence was significantly higher in the intervention group (87.0\%) compared with the usual care group $(76.0 \%)(p<0.001)$

In the 12 months following the program, Pap screening rates were significantly higher in the intervention group (70.0\%) compared to the control group (11.1\%) $(p<0.001)$

Navigation was found to significantly shorten time to consultation for women older than 60 years but not for women 31-60 years of age 
TABLE 1 | Continued

\begin{tabular}{llll}
\hline Reference & Cancer & \multicolumn{1}{c}{ Design } & \multicolumn{1}{c}{ Participants } \\
\hline Battaglia et al. (33) & $\begin{array}{l}\text { Breast, } \\
\text { cervical }\end{array}$ & $\begin{array}{l}\text { Quasi- } \\
\text { experimental } \\
\text { intervention }\end{array}$ & $\begin{array}{l}\text { Women with abnormal breast and cervical } \\
\text { cancer screenings who were enrolled in the } \\
\text { navigator intervention }(n=1,497) \text { or usual care } \\
(n=1,544) \text { arm in the Boston Patient Navigation } \\
\text { Research Program }\end{array}$ \\
& & & \\
Charlot et al. (34) & Breast, \\
& cervical & $\begin{array}{l}\text { Quasi- } \\
\text { experimental } \\
\text { intervention }\end{array}$ & $\begin{array}{l}\text { Women with a breast }(n=655) \text { or cervical } \\
(n=602) \text { cancer screening abnormality enrolled } \\
\text { in the Boston Patient Navigation Research } \\
\text { Program }\end{array}$
\end{tabular}

\begin{tabular}{|c|c|c|c|}
\hline Donelan et al. (35) & Breast & $\begin{array}{l}\text { Group } \\
\text { comparison } \\
\text { study }\end{array}$ & $\begin{array}{l}72 \text { women with abnormal mammography } \\
\text { enrolled in a navigator program. } 181 \text { women } \\
\text { with abnormal mammography were in the non- } \\
\text { navigated group }\end{array}$ \\
\hline Dudley et al. (36) & Breast & $\begin{array}{l}\text { Quasi- } \\
\text { experimental } \\
\text { intervention }\end{array}$ & $\begin{array}{l}460 \text { low-income Hispanic women (260 } \\
\text { navigated, } 200 \text { usual care) with an abnormal } \\
\text { breast cancer screening result or untreated } \\
\text { biopsy in the University of Texas Patient } \\
\text { Navigation Research Program }\end{array}$ \\
\hline Freund et al. (37) & Breast & Meta analyses & $\begin{array}{l}3,083 \text { women with abnormal breast cancer } \\
\text { screening tests and } 1,455 \text { women with } \\
\text { abnormal cervical cancer screening tests who } \\
\text { participated in the Patient Navigation Research } \\
\text { Program }\end{array}$ \\
\hline
\end{tabular}

Hoffman et al. (38) Breast Prospective, 2,601 women (1,047 navigated, 1,554 usual pre-post study care) with abnormal breast cancer screening result/clinical abnormality enrolled in the DC City-wide Patient Navigation Research Program Lee et al. (39) Breast Controlled 1,039 (494 navigated, 545 usual care) women cluster ․ with abnormal breast cancer screening result/ randomized trial clinical abnormality enrolled in the Moffitt Patient design Navigation Research Program

Luckett et al. (40) Cervical, Descriptive vulvar study

Markossian et al. Breast, Quasi(41) cervical experimental intervention

4,199 women at a tertiary care referral colposcopy center implementing a patient navigator program to reduce non-show rates Underserved women with abnormal breast or cervical screening test results were assigned to either patient navigation intervention ( $n=355)$ (the Chicago Cancer Navigation Project) or usual care groups ( $n=413$ )

Paskett et al. (42) Cervical Meta-analysis

Percac-Lima et al. Cervical Quasi(43) experimental intervention

Raich et al. (44) Breast Randomized clinical trial
2,317 women with low and high-risk cervical abnormalities from four Patient Navigation Program centers who received patient navigation ( $n=1332)$ or usual care $(n=985)$

533 Latina women with an abnormal Pap smear requiring colposcopy received patient navigation. The comparison group was 253 non-navigated Latinas with an abnormal Pap smear requiring colposcopy 628 patients with abnormal breast screenings tests randomized to either intervention $(n=308)$ or usual care $(n=320)$ arms in the Denver Patient Navigation Research Program

\section{Results}

There was a significant decrease in time to diagnostic resolution for navigated group compared with usual care group among those with a cervical screening abnormality ( $\mathrm{aHR}=1.46$; $95 \%$ $\mathrm{Cl}=1.1-1.9$ ); and among those with a breast cancer screening abnormality that resolved after 60 days (aHR $=1.40 ; 95 \%$ $\mathrm{Cl}=1.1-1.9)$. There was no difference before 60 days Language concordance was associated with timelier diagnostic resolution for all women of the cervical cancer screening abnormality group during the first 90 days (aHR $=1.46 ; 95 \%$ $\mathrm{Cl}=1.18-1.80$ ), but not after 90 days. Race concordance was associated with significant decreases in time to diagnostic resolution for minority women with breast and cervical cancer abnormalities

There was no difference in timeliness of care, preparation for the visit to the breast center, ease of access, quality of care, provider communication, unmet needs, and patient satisfaction between groups

The average days from definitive diagnosis to initiation of therapy was significantly reduced overall with navigation (navigation vs. usual care, 57 vs. 74 days, $p<0.05$ )

One out of seven sites focused on abnormal breast cancer screening and two out of four sites focused on abnormal cervical cancer screening reported a significant benefit of $\mathrm{PN}$ on diagnostic resolution after cancer screening abnormality from 0 to 90 days

Three out of seven sites focused on abnormal breast cancer screening and 2 out of four sites focused on abnormal cervical cancer screening reported a significant benefit of PN during 91-365 days

The average number of days to diagnostic resolution was significantly shorter for navigated women than non-navigated women (25.1 vs. 42.1 days, respectively, $p<0.001$ ), particularly among women who had a biopsy $(p<0.001)$

Patient navigation did not increase the timeliness of diagnostic resolution during the initial 3 months of follow-up but started to reduce time to diagnostic resolution after 3 months $(\mathrm{aHR}=2.8$, $95 \% \mathrm{Cl}=1.30-6.13)$ and had a significant effect after 4.7 months $(p<0.05)$

No-show rates declined from 49.7 to $29.5 \%$ after implementation of the patient navigator program

Compared with the usual care group, the breast navigation group had shorter time to diagnostic resolution (aHR $=1.65,95 \%$ $\mathrm{Cl}=1.20-2.28)$ and the cervical navigation group had shorter time to diagnostic resolution for those who resolved after 30 days $(\mathrm{aHR}=2.31,95 \% \mathrm{Cl}=1.75-3.06)$, with no difference before 30 days

Low-risk women in the navigated group showed improvement in timely diagnostic follow-up in all racial groups, but significant effects were only observed in non-English speaking Hispanic women $(\mathrm{OR}=5.88,95 \% \mathrm{Cl}=2.81-12.29)$. No effect was observed in high-risk women

Navigated women had significantly fewer missed colposcopy appointments over time, with the average falling from 19.8 to $15.7 \%(p<0.05)$, compared with an insignificant increase in the no-show rates from 18.6 to $20.6 \%$ in the comparison group

For the abnormal breast screening group, 92\% of the navigated patients reached diagnostic resolution of the initial abnormal test, as compared with $77 \%$ for the usual care patients $(p<0.001)$ 
TABLE 1 | Continued

\begin{tabular}{|c|c|c|c|c|}
\hline Reference & Cancer & Design & Participants & Results \\
\hline Ramirez et al. (45) & Breast & $\begin{array}{l}\text { Prospective, } \\
\text { pre-post study }\end{array}$ & $\begin{array}{l}425 \text { Latina women with abnormal breast cancer } \\
\text { screening results enrolled in either a patient } \\
\text { navigator program (Six Cities Patient Navigation } \\
\text { Study) ( } n=217) \text { or usual care }(n=208)\end{array}$ & $\begin{array}{l}\text { The time to diagnosis was shorter in the navigated group } \\
\text { (mean, } 32.5 \text { vs. } 44.6 \text { days in the usual care group; } H R=1.32 \text { ). } \\
\text { Navigation significantly shortened the time to diagnosis among } \\
\text { women who had BI-RADS-3 radiologic abnormalities (mean, } \\
21.3 \text { vs. } 63.0 \text { days; HR }=2.42 \text { ); but not among those who had } \\
\text { BI-RADS- } 4 \text { or } 5 \text { (mean, } 37.6 \text { vs. } 36.9 \text { days; HR }=0.98 \text { ) }\end{array}$ \\
\hline
\end{tabular}

\section{PATIENT NAVIGATION AFTER PRIMARY DIAGNOSIS}

\begin{tabular}{|c|c|c|c|c|}
\hline Chen et al. (46) & Breast & $\begin{array}{l}\text { Pre-post } \\
\text { design, quasi- } \\
\text { experimental } \\
\text { intervention }\end{array}$ & $\begin{array}{l}100 \text { newly diagnosed women with breast } \\
\text { cancer who were enrolled in a navigator } \\
\text { program }(n=51) \text { and non-navigated }(n=49)\end{array}$ & $\begin{array}{l}\text { Overall adherence to the quality indicators significantly improved } \\
\text { from } 69 \text { to } 86 \%(p<0.01) \text { with the use of patient navigators. } \\
\text { Only one individual indicator, use of surveillance mammography, } \\
\text { significantly improved }(52-76 \%, p<0.05) \text { for the navigated } \\
\text { women, not for the non-navigated women }\end{array}$ \\
\hline $\begin{array}{l}\text { Haideri and } \\
\text { Moormeier (47) }\end{array}$ & Breast & $\begin{array}{l}\text { Retrospective } \\
\text { case series } \\
\text { analysis }\end{array}$ & $\begin{array}{l}157 \text { women who received navigation services } \\
\text { and } 103 \text { women who received usual care after } \\
\text { being diagnosed with breast cancer }\end{array}$ & $\begin{array}{l}\text { There was no difference in the stage of presentation or the overall } \\
\text { survival between the intervention and usual care groups. For the } \\
\text { navigated women, there was a modest decrease ( } 9 \text { days) in the } \\
\text { time between initial presentation and definitive therapy }\end{array}$ \\
\hline Hendren et al. (48) & Breast & $\begin{array}{l}\text { Randomized } \\
\text { controlled trial }\end{array}$ & $\begin{array}{l}319 \text { newly diagnosed breast cancer patients } \\
\text { were randomized to receive a patient navigation } \\
\text { intervention for improved quality of life }(n=141) \\
\text { or usual care }(n=129) \text { in the University of } \\
\text { Rochester Patient Navigation Project }\end{array}$ & $\begin{array}{l}\text { There was no significant effect of patient navigation on disease- } \\
\text { specific quality of life scores between navigated and usual care } \\
\text { breast cancer patients undergoing primary cancer treatment }\end{array}$ \\
\hline Ko et al. (49) & Breast & $\begin{array}{l}\text { Multisite, quasi- } \\
\text { experimental } \\
\text { intervention }\end{array}$ & $\begin{array}{l}1,004 \text { (navigated }=498 \text {, usual care }=506 \text { ) } \\
\text { women newly diagnosed with breast cancer } \\
\text { enrolled in the Patient Navigation Research } \\
\text { Program to improve receipt of recommended } \\
\text { care }\end{array}$ & $\begin{array}{l}\text { Among women eligible for antiestrogen therapy, navigated women } \\
\text { had a significant higher likelihood of receiving antiestrogen therapy } \\
\text { compared with non-navigated controls }(\mathrm{OR}=1.73, p<0.01) \text {. } \\
\text { Among the women eligible for radiation therapy after lumpectomy, } \\
\text { navigated women were no more likely to receive radiation than } \\
\text { women in the usual care group (OR }=1.42, p=0.22)\end{array}$ \\
\hline Madore et al. (50) & Breast & $\begin{array}{l}\text { Quasi- } \\
\text { experimental } \\
\text { pilot study }\end{array}$ & $\begin{array}{l}20 \text { medically underserved women recently } \\
\text { diagnosed with breast cancer who were } \\
\text { enrolled in the Breast CARES intervention to } \\
\text { overcome treatment barriers }\end{array}$ & $\begin{array}{l}\text { There was a decrease in depression and cancer-related distress } \\
\text { and an increase in social support. Participation in the intervention } \\
\text { helped the women overcome financial barriers }(73.0 \%) \text {, } \\
\text { transportation problems }(60.0 \%) \text {, and communication barriers } \\
\text { with medical staff }(73.0 \%)\end{array}$ \\
\hline Raj et al. (51) & Breast & $\begin{array}{l}\text { Retrospective, } \\
\text { pre-post study }\end{array}$ & $\begin{array}{l}186 \text { women with breast cancer from a } \\
\text { disadvantaged minority community who } \\
\text { participated in a patient navigator program to } \\
\text { improve quality measures }\end{array}$ & $\begin{array}{l}\text { Women who received navigation services received high-quality } \\
\text { cancer care, as defined by concordance with ASCO/NCCN } \\
\text { quality measures. These navigated women also had a favorable } \\
\text { breast cancer stage distribution with }>50 \% \text { having in situ or stage } \\
1 \text { disease }\end{array}$ \\
\hline Ramirez et al. (52) & Breast & $\begin{array}{l}\text { Quasi- } \\
\text { experimental } \\
\text { intervention }\end{array}$ & $\begin{array}{l}480 \text { Latinas with breast cancer enrolled in } \\
\text { either a patient navigation program for timely } \\
\text { diagnostic resolution ( } n=251) \text { or usual care } \\
(n=229) \text { in the Six Cities Study }\end{array}$ & $\begin{array}{l}\text { A significantly higher percentage of navigated women initiated } \\
\text { treatment within } 30 \text { days }(69.0 \text { vs. } 46.3 \%, p<0.05) \text { and } 60 \text { days } \\
\text { ( } 97.6 \text { vs. } 73.1 \%, p<0.001) \text { compared to women in the usual } \\
\text { care group. Time from cancer diagnosis to first treatment was } \\
\text { significantly lower in the navigated group ( } 22.22 \text { days) than usual } \\
\text { care group ( } 48.30 \text { days) }\end{array}$ \\
\hline Ulloa et al. (53) & Breast & $\begin{array}{l}\text { Prospective, } \\
\text { pre-post study }\end{array}$ & $\begin{array}{l}130 \text { low-income women from California enrolled } \\
\text { in a patient navigation intervention to improve } \\
\text { communication about survivorship care }\end{array}$ & $\begin{array}{l}\text { The intervention significantly improved short-term recall of } \\
\text { patient-specific breast cancer knowledge }(p=0.05) \text { and reduced } \\
\text { communication barriers ( } 15.0 \% \text { at week } 1 \text { to } 6 \% \text { at } 3 \text { months, } p<0.05 \text { ) }\end{array}$ \\
\hline
\end{tabular}

the previous year, with the proportion increasing to $67 \%$ after 1 -year $(p=0.001)$ of receiving the education-based PN intervention. Lastly, another study by Percac-Lima et al. (29) found that an education-based PN intervention to overcome barriers to breast cancer screening and information on how to obtain mammogram screening when needed among Somali, Arabic, or Serbo-Croatian refugee women improved mammography rates and significantly decreased disparities in screening rates between refugee and English- and Spanish-speaking women receiving care at the same health center.

One study in our review examined the impact of $\mathrm{PN}$ on screening rates for gynecological cancers. Wang et al. (31) found Chinese women in need of a Pap test reported significantly higher Pap test screening rates for those who received the PN intervention (education and $\mathrm{PN}$ services) compared to the control group (education only) (70 vs. $11.1 \%$, respectively, $p<0.001)$.

\section{PN for Diagnostic Resolution}

Six studies $(32,35,36,38,39,45)$ were identified that focused on $\mathrm{PN}$ interventions to reduce time from abnormal breast cancer screening to diagnostic resolution. Of the six studies, one RCT by Lee et al. (39) examined the efficacy of PN among medically underserved populations in Tampa, FL, USA. Results showed a lagged effect of PN; PN did not increase the timeliness of diagnostic resolution during the initial 3 months of follow-up [adjusted hazard ratio $(\mathrm{aHR})=0.85,95 \% \mathrm{CI}=0.64-1.13$ ], but reduced the time to diagnostic resolution after 3 months 
$(\mathrm{aHR}=2.8395 \% \mathrm{CI}=1.30-6.13)$ and had a significant effect $(p<0.05)$ after 4.7 months. Several quasi-experimental studies $(32,36,38,45)$ on $\mathrm{PN}$ and diagnostic resolution for abnormal breast cancer screening reported that $\mathrm{PN}$ significantly shortened time to diagnostic resolution compared to women who did not receive PN. One cohort study (35) exploring patient perspectives of clinical care and $\mathrm{PN}$ in follow-up of abnormal mammography reported no differences in the timeliness of care, preparation for the visit to the breast center, ease of access, quality of care, provider communication, unmet needs, and patient satisfaction between navigated and non-navigated groups.

Three studies, a meta-analysis (42), descriptive study (40), and quasi-experimental study (43), were published during the time period reviewed that examined $\mathrm{PN}$ for diagnostic resolution of an abnormal cervical cancer screening result. A recent meta-analysis by Paskett et al. (42) examined the effectiveness of PN for diagnostic resolution of an abnormal cervical cancer screening among four PNRP centers. Within these centers, low-risk women in the navigated group showed improvement in timely diagnostic follow-up in all racial groups, but statistically significant effects were only observed in non-English speaking Hispanic women $(\mathrm{OR}=5.88,95 \% \mathrm{CI}=2.81-12.29)$. No effect was observed in high-risk women. A pre-post study (40) implemented a PN program to reduce no-show rates at a colposcopy center. After implementation, no-show rates for abnormal Pap test follow-up declined from 49.7 to $29.5 \%$ ( $p<0.0001)$. In another quasi-experimental study (43) focused on Latinas in need of abnormal Pap test follow-up, navigated women had significantly fewer missed colposcopy appointments over time (i.e., reduction from 19.8 to $15.7 \% ; p=0.02$ ) compared with an insignificant increase in no-show rates from 18.6 to $20.6 \%$ in the comparison group.

Three studies $(33,34,41)$ explored $\mathrm{PN}$ interventions with regard to diagnostic resolution after an abnormal breast or cervical cancer screening test. A study by Markossian et al. (41) reported $\mathrm{PN}$ for abnormal breast cancer screening was associated with shorter time to diagnostic resolution $(\mathrm{aHR}=1.65$, $95 \% \mathrm{CI}=1.20-2.28, p=0.002$ ). However, there was a lag in the effectiveness of $\mathrm{PN}$ regarding diagnostic resolution for abnormal cervical cancer screening. In the first 30 days, the difference between those in the PN arm vs. those in the comparison group was not significant. But, from days 31 to 365 , women in the PN group experienced a shorter time to diagnostic resolution compared with those women who received usual care $(\mathrm{aHR}=2.31$, 95\% CI $=1.75-3.06, p<0.001)$. A similar trend was noted by Battaglia et al. (33) among participants with an abnormal breast and cervical cancer screening test. Conversely, Charlot et al. (34) found a language concordance PN intervention was associated with timelier resolution for the cervical cancer screening abnormalities group during the first 90 days (aHR $=1.46,95 \%$ $\mathrm{CI}=1.18-1.80$ ), but not after 90 days. No significant difference was found between the navigated and non-navigated breast cancer screening abnormality groups throughout the course of the study.

The PNRP studies included other cancers (colorectal and prostate), but the majority of the cancers were breast and cervical. A meta-analysis by Freund et al. (37) assessed the timeliness of diagnostic resolution for an abnormal breast and cervical cancer screening result across the PNRP. The results of the meta-analysis found little benefit during the first 90 days of care as only one of the seven sites focusing on breast cancer screening and two of the four sites focusing on cervical cancer screening observed a positive effect of PN on time to diagnostic resolution $(p<0.05)$. Greater benefit from navigation was seen from 91 to 365 days for diagnostic resolution among three of the seven sites focused on breast cancer screening and two of the four sites focused on cervical cancer screening $(p<0.05)$. Meta-regression revealed that navigation had its greatest benefits within centers with the greatest delays in follow-up under usual care.

One study (44) reported on the difference in time to diagnostic resolution between those in the PN intervention vs. control groups. A RCT from the Denver PNRP center evaluated the effectiveness of $\mathrm{PN}$ programs for increasing rates of diagnostic resolution for abnormal breast cancer screening. Raich et al. (44) found $\mathrm{PN}$ shortened time to resolution in the navigated group $(p<0.001)$ compared to the usual care group. Specifically, PN improved diagnostic resolution for patients presenting with mammographic BIRADS 0 and 3, but not BIRADS 4/5 or abnormal breast examinations.

\section{PN after Diagnosis}

The results of the literature review for PN after cancer diagnosis resulted in eight studies (46-53), including one RCT (48), reporting effects on various outcomes among cancer patients including start of treatment, receipt of recommended care, completion of treatment, quality of life and depressive symptoms, communication with physicians, and quality measures. Hendren et al. (48) found no significant effect of PN on disease-specific quality of life scores between navigated and usual care breast cancer patients from baseline to 3 months. Other studies suggest that PN had no effect on time to completion of primary cancer treatment, satisfaction with cancer-related care, or psychological distress, and they attributed the non-significant findings to the open eligibility criteria (all patients) instead of targeting those with shown need, as seen in other effective interventions $(49,51,52)$.

A study by Ramirez et al. (52) sought to examine the effectiveness of $\mathrm{PN}$ in reducing time from breast cancer diagnosis to initiation of treatment among Hispanic/Latino women. Compared to control patients, there was a significantly higher percentage of navigated women who initiated treatment within 30 days ( 69.0 vs. $46.3 \%, p<0.05$, intervention vs. control, respectively) and 60 days ( 97.6 vs. $73.1 \%, p<0.001$, intervention vs. control, respectively) from diagnosis. Also, time from breast cancer diagnosis to first treatment was significantly lower in the navigated group (22.22 days) than among women in the control group (48.30 days).

In a large, multisite study, Ko et al. (49) sought to improve the receipt of recommended care for newly diagnosed breast cancer patients, and the findings varied based on the type of treatment received by the patients. Among women eligible for antiestrogen therapy, navigated participants were more likely to receive antiestrogen therapy compared with usual care participants $(\mathrm{OR}=1.73, p=0.004)$. Among women eligible for radiation therapy after lumpectomy, navigated participants were 
no more likely to receive radiation than usual care participants $(\mathrm{OR}=1.42, p=0.22)$.

\section{Barriers to Care and PN}

Several studies have conducted secondary analyses to understand the association between barriers to care and clinical outcomes, particularly within the PNRP. A 2015 study by Ramachandran et al. (54) explored the association among number of barriers to care, type of barriers, and timeliness of diagnostic resolution among women with abnormal cancer screening results. They found that $74 \%$ of breast cancer screening participants and 55\% of cervical cancer screening participants reported at least one barrier to diagnostic resolution. Navigated women with barriers resolved cancer screening abnormalities at a slower rate compared with navigated women with no barriers. Another study by Ramachandran et al. (55) using Boston PNRP data, found the odds of timely diagnostic resolution reduced as the number of barriers increased (one barrier, aHR $=0.81,95 \% \mathrm{CI}=0.56-1.17, p=0.26$; two barriers, $\mathrm{aHR}=0.55,95 \% \mathrm{CI}=0.37-0.81, p=0.0025$; three or more barriers, aHR $=0.31,95 \% \mathrm{CI}=0.21-0.46, p<0.0001)$. Lastly, Katz et al. (56) examined the effect of having barriers to diagnostic resolution and time to resolution among participants in the PN intervention arm with a breast or cervical cancer abnormality in the PNRP. They found that $63.7 \%$ of breast abnormality and $46.6 \%$ of cervical abnormality participants had at least one barrier resulting in longer time to diagnostic resolution among breast $(\mathrm{aHR}=0.74,95 \% \mathrm{CI}=0.67-0.83, p<0.01)$ and cervical $(\mathrm{aHR}=0.79,95 \% \mathrm{CI}=0.70-0.90, p<0.01)$ participants vs. those with no reported barriers.

Specific types of barriers patients report were described by several studies (57-59). Korber et al. (57) found the most common barriers to cancer treatment were patient-provider communication and knowledge of patient resources. Other studies found location of health-care facility (59), transportation problems (58), not speaking English (55), no insurance (56), financial concerns $(58,60)$, lack of social/practical support $(58$, 59), and lack of information about the abnormality (57) as the most prevalent barriers to cancer care among patients enrolled in $\mathrm{PN}$ interventions.

Some studies have attempted to determine which variables are associated with having a barrier to cancer care to identify women most in need of PN. Several studies (55, 60-62) found that women with barriers to cancer care were more likely to be racial and ethnic minorities $(55,60)$, unmarried (62), part-time employed/unemployed $(60,62)$, non-English language speakers $(55,61)$, and have public/no health insurance $(55,60)$ compared to women without any barriers to care.

\section{DISCUSSION}

As evidenced in this literature review, PN has been shown to help women receive cancer screenings, receive more timely diagnostic resolution after a breast and cervical cancer screening abnormality, initiate treatment sooner, receive proper treatment, and improve quality of life among cancer patients. Also, it was shown that PN eliminates barriers to care. PNRP demonstrated: (1) who has barriers; (2) that barriers delay the receipt of care; and (3) types of numbers of barriers that impact time to treatment (54-56).

Several trends emerged from this review. PN programs have been implemented among diverse populations specifically focused on reducing health disparities in racial and ethnic minorities and/or underserved populations. It is important to note that each study population and setting was unique, thus generalizability of these findings may be limited. Another trend noted was the limited effectiveness for certain groups receiving $\mathrm{PN}$, alluding to the possibility that $\mathrm{PN}$ is not equally effective for all groups. Results found significant differences in PN effectiveness with regard to age (32), ethnicity (42), location of care (37), type of screening test (38), and type of treatment (49). Although relevant for all populations, use of a "one-size-fits all" approach to $\mathrm{PN}$ may not be the best approach. The original intent of $\mathrm{PN}$ is to improve the experience of care among patients with the greatest needs by tailoring actions to an individual's barriers to care (63). If implementation across the patient population is too demanding on resources, especially due to the fact that the American College of Surgeons Commission on Cancer (CoC)'s accreditation mandates are currently unfunded, targeting PN implementation may be a possible solution. By identifying those most likely to need $\mathrm{PN}$, scarce resources can be diverted to women in most need and most likely to delay or not receive prompt, appropriate care (64).

Finally, although there is evidence of the potential of PN to improve outcomes related to cancer screening and diagnostic resolution, many studies have utilized less robust designs (i.e., quasi-experimental and descriptive studies), as mentioned by previous reviews (14-16). A notable difference between this review and the prior reviews is an increase in the number of studies evaluating PN on cancer screening and treatment outcomes. Another difference between this and previous reviews was inclusion of studies that evaluated the association of $\mathrm{PN}$ with reported outcomes during cancer treatment and post-treatment. Yet, there was great heterogeneity among the studied outcomes (e.g., quality of life, proper treatment), and therefore, cumulative evidence, as seen in $\mathrm{PN}$ interventions on cancer screening and diagnostic resolution, is lacking.

\section{Research Opportunities in PN and Women's Health}

Due to the increased prevalence of PN in health-care systems, there are growing research opportunities in PN and women's health. One area that is ripe for researchers is $\mathrm{PN}$ in cancer survivorship, particularly among post-treatment cancer survivors. Increases in the number of individuals diagnosed with cancer each year, as well as improving survival rates, have led to an ever-increasing number of cancer survivors (20). As evidenced by this review, implementation of $\mathrm{PN}$ interventions among posttreatment cancer survivors is lacking. Future research should not only explore adherence to post-treatment surveillance behaviors but also treatment outcomes that can affect the physical and psychological well-being of women.

The PN literature on women's cancers is growing; however, it is limited in that researchers have primarily focused on breast cancer (as seen in the literature on PN after diagnosis). Although 
cervical cancer incidence and mortality rates have steadily decreased, it is estimated that in $2015,12,900$ new cases of invasive cervical cancer occurred and 4,100 died from this disease (19). There is a wide racial and socioeconomic disparity in the incidence and mortality rates from cervical cancer. Underlying these disparities are often education, language, geographic, and trust factors (65). As evidenced by this review, the few studies that have explored PN in gynecological cancers showed promising results. Thus, researchers should make gynecological cancers a focus for their PN interventions to maximize the positive impact on this survivor population. Important yet understudied subpopulations, such as women with increased genetic risk, should be considered. PN can provide education, support, and guidance within the clinical setting for these women to receive appropriate screenings, genetic testing and counseling, prompt diagnosis, and proper treatment.

Women may also benefit from PN during cancer care that is tailored to specific family-related barriers, such as child care and transportation. Women often assume the role of caregivers and income-earners and may need more assistance in caregiving for others while receiving cancer care for themselves. PN can link them to resources that offer emotional (i.e., support groups) and tangible support (i.e., house cleaning, child care) and has the potential to improve quality of life and psychosocial outcomes for both women with cancer and women who are caregivers.

Navigators should consider the age of the female patient and their stage in life during PN interventions. For example, younger women often face very different challenges and complications than older women, including concerns about becoming a mother; caring for children when faced with a life-threatening illness; premature menopause leading to loss of fertility; sudden onset of vasomotor symptoms; long-term consequences of early ovarian decline; body image and sexuality; and career and work concerns related to productivity and job security (66). For older

\section{REFERENCES}

1. Ward E, Jemal A, Cokkinides V, Singh GK, Cardinez C, Ghafoor A, et al. Cancer disparities by race/ethnicity and socioeconomic status. CA Cancer J Clin (2004) 54:78-93. doi:10.3322/canjclin.54.2.78

2. Gehlert S, Colditz GA. Cancer disparities: unmet challenges in the elimination of disparities. Cancer Epidemiol Biomarkers Prev (2011) 20:1809-14. doi:10.1158/1055-9965.EPI-11-0628

3. Paskett ED, McLaughlin JM, Lehman AM, Katz ML, Tatum CM, Oliveri JM. Evaluating the efficacy of lay health advisors for increasing riskappropriate Pap test screening: a randomized controlled trial among Ohio Appalachian women. Cancer Epidemiol Biomarkers Prev (2011) 20:835-43. doi:10.1158/1055-9965.EPI-10-0880

4. Russell KM, Champion VL, Monahan PO, Millon-Underwood S, Zhao Q, Spacey N, et al. Randomized trial of a lay health advisor and computer intervention to increase mammography screening in African American women. Cancer Epidemiol Biomarkers Prev (2010) 19:201-10. doi:10.1158/1055-9965. EPI-09-0569

5. Freeman HP, Muth BJ, Kerner JF. Expanding access to cancer screening and clinical follow-up among the medically underserved. Cancer Pract (1995) 3:19-30.

6. American College of Surgeons. National Accrediation Program for Breast Centers Breast Center Components. Chicago, IL: American College of Surgeons (2010). adults, age-related concerns may include spousal caregiving; lack of social support; quality vs. quantity of life; comorbidities; risk of polypharmacy; mobility challenges; housing and transportation needs; and declining cognitive function and information processing $(67,68)$. Navigators from the PNRP used a standardized, structured list and an open-ended approach that captured barriers to care identified by participants. Future studies should utilize this approach to collect information on barriers to care and explore age-related differences in reported barriers to address individual needs accordingly.

The similarity of patient navigators to the participants is important for the success of PN interventions. For example, patient navigator race and language concordance improved the timeliness of care in a minority population (34). Likeness to the patient population is already a typical characteristic of CHWs, who work within a target community to improve community awareness and adherence to cancer screenings, and thus, this successful strategy should be extended to navigators. Since the CHWs' role is to connect underserved populations from the community with screening services, $\mathrm{PN}$ programs should work with CHWs to assist women across the entire cancer care spectrum from cancer prevention to post-treatment. Future research should explore the effect of a combined CHW and $\mathrm{PN}$ intervention to increase community engagement, improve access to preventive health services, facilitate timely diagnosis and treatment, and ultimately improve the health of women in underserved areas.

\section{AUTHOR CONTRIBUTIONS}

JK-S was responsible for the planning, literature review, writing, editing, and submitting the manuscript. JO was responsible for the planning, literature review, writing, and editing the manuscript. EP was responsible for the planning, writing, and editing the manuscript.

7. National Comprehensive Cancer Network. The Case Manager or Patient Navigator: Providing Support for Cancer Patients During Treatment and Beyond. Fort Washington, PA: National Comprehensive Cancer Network (2014).

8. Clark CR, Baril N, Kunicki M, Johnson N, Soukup J, Ferguson K, et al. Addressing social determinants of health to improve access to early breast cancer detection. J Womens Health (2009) 18:677-90. doi:10.1089/jwh.2008.0972

9. Fang CY, Ma GX, Tan Y, Chi N. A multifaceted intervention to increase cervical cancer screening among underserved Korean women. Cancer Epidemiol Biomarkers Prev (2007) 16:1298-302. doi:10.1158/1055-9965.EPI-07-0091

10. Battaglia TA, Roloff K, Posner MA, Freund KM. Improving follow-up to abnormal breast cancer screening in an urban population. Cancer (2007) 109:S359-67. doi:10.1002/cncr.22354

11. Ell K, Vourlekis B, Lee PJ, Xie B. Patient navigation and case management following an abnormal mammogram: a randomized clinical trial. Prev Med (2008) 44:26-33. doi:10.1016/j.ypmed.2006.08.001

12. Ell K, Vourlekis B, Xie B, Nedjat-Haiem FR, Lee PJ, Muderspach L, et al. Cancer treatment adherence among low-income women with breast or gynecologic cancer: a randomized controlled trial of patient navigation. Cancer (2009) 115:4606-15. doi:10.1002/cncr.24500

13. Schwaderer KA, Proctor JW, Martz EF, Slack RJ, Ricci E. Evaluation of patient navigation in a community radiation oncology center involved in disparities studies: a time-to-completion-of-treatment study. J Oncol Pract (2008) 4: 220-4. doi:10.1200/JOP.0852001 
14. Robinson-White S, Conroy B, Slavish KH, Rosenzweig M. Patient navigation in breast cancer: a systematic review. Cancer Nurs (2010) 33(2):127-40. doi:10.1097/NCC.0b013e3181c40401

15. Paskett ED, Harrop JP, Wells KJ. Patient navigation: an update on the state of the science. CA Cancer J Clin (2011) 61(4):237-49. doi:10.3322/caac.20111

16. Wells KJ, Battaglia TA, Dudley DJ, Garcia R, Greene A, Calhoun E, et al. Patient navigation: state of the art or is it science? Cancer (2008) 113(8):1999-2010. doi:10.1002/cncr.23815

17. Simard S, Thewes B, Humphris G, Dixon M, Hayden C, Mireskandari S, et al. Fear of cancer recurrence in adult cancer survivors: a systematic review of quantitative studies. J Cancer Surviv (2013) 7(3):300-22. doi:10.1007/ s11764-013-0272-Z

18. Freund KM, Battaglia TA, Calhoun E, Dudley DJ, Fiscella K, Paskett E, et al. National cancer institute patient navigation research program. Cancer (2008) 113:3391-9. doi:10.1002/cncr.23960

19. American Cancer Society. Cancer Facts and Figures, 2015. Atlanta, GA: American Cancer Society (2015).

20. Siegel R, Ma J, Zou Z, Jemal A. Cancer statistics, 2014. CA Cancer J Clin (2014) 64:9-29. doi:10.3322/caac. 21208

21. Paskett ED, Katz ML, Post DM, Pennell ML, Young GS, Seiber EE, et al. The Ohio patient navigation research program: does the American cancer society patient navigation model improve time to resolution in patients with abnormal screening tests? Cancer Epidemiol Biomarkers Prev (2012) 21(10):1620-8. doi:10.1158/1055-9965.EPI-12-0523

22. Warren-Mears V, Dankovchik J, Patil M, Fu R. Impact of patient navigation on cancer diagnostic resolution among northwest tribal communities. J Cancer Educ (2013) 28(1):109-18. doi:10.1007/s13187-012-0436-y

23. Wells KJ, Lee JH, Calcano ER, Meade CD, Rivera M, Fulp WJ, et al. A cluster randomized trial evaluating the efficacy of patient navigation in improving quality of diagnostic care for patients with breast or colorectal cancer abnormalities. Cancer Epidemiol Biomarkers Prev (2012) 21(10):1664-72. doi:10.1158/1055-9965.EPI-12-0448

24. Fiscella K, Whitley E, Hendren S, Raich P, Humiston S, Winters P, et al. Patient navigation for breast and colorectal cancer treatment: a randomized trial. Cancer Epidemiol Biomarkers Prev (2012) 21(10):1673-81. doi:10.1158/10559965.EPI-12-0506

25. Wagner EH, Ludman EJ, Aiello Bowles EJ, Penfold R, Reid RJ, Rutter CM, et al. Nurse navigators in early cancer care: a randomized, controlled trial. $J$ Clin Oncol (2014) 32:12-8. doi:10.1200/JCO.2013.51.7359

26. Burhansstipanov L, Dignan MB, Schumacher SA, Krebs LU, Alfonsi G, Apodaca CC. Breast screening navigator programs within three settings that assist underserved women. J Cancer Educ (2010) 25:247-52. doi:10.1007/ s13187-010-0071-4

27. Marshall JK, Mbah OM, Ford JG, Phelan-Emrick D, Ahmed S, Bone L, et al. Effect of patient navigation on breast cancer screening among African American Medicare beneficiaries: a randomized controlled trial. J Gen Intern Med (2015) 31(1):68-76. doi:10.1007/s11606-015-3484-2

28. Percac-Lima S, Milosavljevic B, Oo SA, Marable D, Bond B. Patient navigation to improve breast cancer screening in Bosnian refugees and immigrants. $J$ Immigr Minor Health (2012) 14:727-30. doi:10.1007/s10903-011-9539-5

29. Percac-Lima S, Ashburner JM, Bond B, Oo SA, Atlas SJ. Decreasing disparities in breast cancer screening in refugee women using culturally tailored patient navigation. J Gen Intern Med (2013) 28(11):1463-8. doi:10.1007/ s11606-013-2491-4

30. Phillips CE, Rothstein JD, Beaver K, Sherman BJ, Freund KM, Battaglia TA. Patient navigation to increase mammography screening among inner city women. J Gen Intern Med (2011) 26(2):123-9. doi:10.1007/s11606-010-1527-2

31. Wang X, Fang C, Tan Y, Liu A, Ma GX. Evidence-based intervention to reduce access barriers to cervical cancer screening among underserved Chinese American women. J Womens Health (2010) 19(3):463-9. doi:10.1089/ jwh.2009.1422

32. Basu M, Linebarger J, Gabram SG, Patterson SG, Amin M, Ward KC. The effect of nurse navigation on timeliness of breast cancer care at an academic comprehensive cancer center. Cancer (2013) 119(14):2524-31. doi:10.1002/ cncr. 28024

33. Battaglia TA, Bak SM, Heeren T, Chen CA, Kalish R, Tringale S, et al. Boston patient navigation research program: the impact of navigation on time to diagnostic resolution after abnormal cancer screening. Cancer Epidemiol Biomarkers Prev (2012) 21(10):1645-54. doi:10.1158/1055-9965.EPI-12-0532
34. Charlot M, Santana MC, Chen CA, Bak S, Heeren TC, Battaglia TA, et al. Impact of patient and navigator race and language concordance on care after cancer screening abnormalities. Cancer (2015) 121(9):1477-83. doi:10.1002/ cncr. 29221

35. Donelan K, Mailhot JR, Dutwin D, Barnicle K, Oo SA, Hobrecker K, et al. Patient perspectives of clinical care and patient navigation in follow-up of abnormal mammography. J Gen Intern Med (2011) 26(2):116-22. doi:10.1007/ s11606-010-1436-4

36. Dudley DJ, Drake J, Quinlan J, Holden A, Saegert P, Karnard A, et al. Beneficial effects of a combined navigator/promotora approach for Hispanic women diagnosed with breast abnormalities. Cancer Epidemiol Biomarkers Prev (2012) 21(10):1639-44. doi:10.1158/1055-9965.EPI-12-0538

37. Freund KM, Battaglia TA, Calhoun E, Darnell JS, Dudley DJ, Fiscella K, et al. Impact of patient navigation on timely cancer care: the patient navigation research program. J Natl Cancer Inst (2014) 106(6):dju115. doi:10.1093/jnci/ dju115

38. Hoffman HJ, LaVerda NL, Young HA, Levine PH, Alexander LM, Brem R, et al. Patient navigation significantly reduces delays in breast cancer diagnosis in the District of Columbia. Cancer Epidemiol Biomarkers Prev (2012) 21(10):1655-63. doi:10.1158/1055-9965.EPI-12-0479

39. Lee JH, Fulp W, Wells KJ, Meade CD, Calcano E, Roetzheim R. Patient navigation and time to diagnostic resolution: results for a cluster randomized trial evaluating the efficacy of patient navigation among patients with breast cancer screening abnormalities, Tampa, FL. PLoS One (2013) 8(9):e74542. doi:10.1371/journal.pone.0074542

40. Luckett R, Pena N, Vitonis A, Bernstein MR, Feldman S. Effect of patient navigator program on no-show rates at an academic referral colposcopy clinic. $J$ Womens Health (2015) 24(7):608-15. doi:10.1089/jwh.2014.5111

41. Markossian TW, Darnell JS, Calhoun EA. Follow-up and timeliness after an abnormal cancer screening among underserved, urban women in a patient navigation program. Cancer Epidemiol Biomarkers Prev (2012) 21(10): 1691-700. doi:10.1158/1055-9965.EPI-12-0535

42. Paskett ED, Dudley DJ, Young GS, Brewer B, Wells KJ, Calhoun E, et al. Impact of patient navigation interventions on timely diagnostic follow-up for abnormal cervical cancer screening. J Womens Health (2016) 25:15-21. doi:10.1089/jwh.2014.5094

43. Percac-Lima S, Benner CS, Liu R, Aldrich LS, Oo SA, Regan N, et al. The impact of a culturally tailored patient navigator program on cervical cancer prevention in Latina women. J Womens Health (2013) 22(5):426-31. doi:10.1089/jwh.2012.3900

44. Raich PC, Whitley EM, Thorland W, Valverde P, Fairclough D. Patient navigation improves cancer diagnostic resolution: an individually randomized clinical trial in an underserved population. Cancer Epidemiol Biomarkers Prev (2012) 21(10):1629-38. doi:10.1158/1055-9965.EPI-12-0513

45. Ramirez AG, Perez-Stable EJ, Penedo FJ, Talavera GA, Carrillo JE, Fernandez ME, et al. Navigating Latinas with breast screen abnormalities to diagnosis: the six cities study. Cancer (2013) 119(7):1298-305. doi: $10.1002 / \mathrm{cncr} .27912$

46. Chen F, Mercado C, Yermilov I, Puig M, Ko CY, Kahn KL, et al. Improving breast cancer quality of care with the use of patient navigators. Am Surg (2010) 76(10):1043-6.

47. Haideri NA, Moormeier JA. Impact of patient navigation from diagnosis to treatment in an urban safety net breast cancer population. J Cancer (2011) 2:467-73. doi:10.7150/jca.2.467

48. Hendren S, Griggs JJ, Epsitein R, Humiston S, Jean-Pierre P, Winters P, et al. Randomized controlled trial of patient navigation for newly diagnosed cancer patients: effects on quality of life. Cancer Epidemiol Biomarkers Prev (2012) 21:1682-90. doi:10.1158/1055-9965.EPI-12-0537

49. Ko NY, Darnell JS, Calhoun E, Freund KM, Wells KJ, Shapiro CL, et al. Can patient navigation improve receipt of recommended breast cancer care? Evidence from the national patient navigation research program. J Clin Oncol (2014) 32(25):2758-64. doi:10.1200/JCO.2013.53.6037

50. Madore S, Kilbourn K, Valverde P, Borrayo E, Raich P. Feasibility of a psychosocial and patient navigation intervention to improve access to treatment among underserved breast cancer patients. Support Care Cancer (2014) 22(8):2085-93. doi:10.1007/s00520-014-2176-5

51. Raj A, Ko N, Battaglia TA, Chabner BA, Moy B. Patient navigation for underserved patients diagnosed with breast cancer. Oncologist (2012) 17:1027-31. doi:10.1634/theoncologist.2012-0191 
52. Ramirez A, Perez-Stable E, Penedo F, Talavera G, Carrillo JE, Fernandez M, et al. Reducing time-to-treatment in underserved Latinas with breast cancer: the six cities study. Cancer (2014) 120(5):752-60. doi:10.1002/cncr.28450

53. Ulloa JG, Hemmelgarn M, Viveros L, Odele P, Feldman NR, Ganz PA, et al. Improving breast cancer survivors' knowledge using a patient-centered intervention. Surgery (2015) 158(3):669-75. doi:10.1016/j.surg.2015.03.056

54. Ramachandran A, Snyder FR, Katz ML, Darnell JS, Dudley DJ, Patierno SR, et al. Barriers to health care contribute to delays in follow-up among women with abnormal cancer screening: data from the patient navigation research program. Cancer (2015) 121:4016-24. doi:10.1002/cncr.29607

55. Ramachandran A, Freund KM, Bak SM, Heeren TC, Chen CA, Battaglia TA. Multiple barriers delay care among women with abnormal cancer screening despite patient navigation. J Womens Health (Larchmt) (2015) 24(1):30-6. doi:10.1089/jwh.2014.4869

56. Katz ML, Young GS, Reiter PL, Battaglia TA, Wells KJ, Sanders M, et al. Barriers reported among patients with breast and cervical abnormalities in the patient navigation research program: impact on timely care. Womens Health Issues (2014) 24(1):e155-62. doi:10.1016/j.whi.2013.10.010

57. Korber SF, Padula C, Gray J, Powell M. A breast navigator program: barriers, enhancers, and nursing interventions. Oncol Nurs Forum (2011) 38(1):44-50. doi:10.1188/11.ONF.44-50

58. Carroll JK, Humiston SG, Meldrum SC, Salamone CM, Jean-Pierre P, Epstein RM, et al. Patients' experiences with navigation for cancer care. Patient Educ Couns (2010) 80:241-7. doi:10.1016/j.pec.2009.10.024

59. Koh C, Nelson JM, Cook PF. Evaluation of a patient navigation program. Clin J Oncol Nurs (2011) 15(1):41-8. doi:10.1188/11.CJON.41-48

60. Primeau SW, Freund KM, Ramachandran A, Bak SM, Heeren T, Chen CA, et al. Social service barriers delay care among women with abnormal cancer screening. J Gen Intern Med (2014) 29(1):169-75. doi:10.1007/ s11606-013-2615-x

61. Karlinger KS, Ma L, Hofmann M, Kerlikowske K. Language barriers, location of care and delays in follow-up of abnormal mammograms. Med Care (2012) 50:171-8. doi:10.1097/MLR.0b013e31822dcf2d
62. Hendren S, Chin N, Fisher S, Winters P, Griggs J, Mohile S, et al. Patients' barriers to receipt of cancer care, and factors associated with needing more assistance from a patient navigator. J Natl Med Assoc (2011) 103(8):701-10. doi:10.1016/S0027-9684(15)30409-0

63. Freeman HP. The origin, evolution, and principles of patient navigation. Cancer Epidemiol Biomarkers Prev (2012) 21(10):1614-7. doi:10.1158/10559965.EPI-12-0982

64. Krok-Schoen JL, Brewer B, Young GS, Weier RC, Tatum CM, DeGraffinreid CR, et al. Participants' barriers to diagnostic resolution and factors associated with needing patient navigation. Cancer (2015) 121:2757-64. doi:10.1002/cncr.29414

65. Natale-Pereira A, Enard KR, Nevarez L, Jones LA. The role of patient navigators in eliminating health disparities. Cancer (2011) 117(Suppl 15):3543-52. doi:10.1002/cncr.26264

66. Manuel JC, Burwell SR, Crawford SL, Lawrence RH, Farmer DF, Hege A, et al. Younger women's perceptions of coping with breast cancer. Cancer Nurs (2007) 30:85-94. doi:10.1097/01.NCC.0000265001.72064.dd

67. Posma ER, van Weert JCM, Jansen J, Bensing JM. Older cancer patients' information and support needs surrounding treatment: an evaluation trough the eyes of patients, relatives and professionals. BMC Cancer (2009) 8:1-15. doi:10.1186/1472-6955-8-1

68. Avis NE, Deimling GT. Cancer survivorship and aging. Cancer (2008) 113(S12):3519-29. doi:10.1002/cncr.23941

Conflict of Interest Statement: The authors declare that the research was conducted in the absence of any commercial or financial relationships that could be construed as a potential conflict of interest.

Copyright (c) 2016 Krok-Schoen, Oliveri and Paskett. This is an open-access article distributed under the terms of the Creative Commons Attribution License (CC BY). The use, distribution or reproduction in other forums is permitted, provided the original author(s) or licensor are credited and that the original publication in this journal is cited, in accordance with accepted academic practice. No use, distribution or reproduction is permitted which does not comply with these terms. 